\title{
QUALIDADE DE SEMENTES DE QUIABEIRO EM FUNÇÃO DA IDADE E DO REPOUSO PÓS-COLHEITA DOS FRUTOS
}

\author{
Okra seed quality as a function of age and fruit post harvest rest
}

\author{
Márcia Maria Castro ${ }^{1}$, Amanda Regina Godoy², Antonio Ismael Inácio Cardoso ${ }^{3}$
}

\begin{abstract}
RESUMO
O trabalho foi conduzido na FCA-UNESP, em Botucatu (SP), objetivando-se estudar o efeito da idade do fruto e o período de repouso pós-colheita sobre a qualidade de sementes de quiabeiro cv. Santa Cruz-47 (Abelmoschus esculentus Moench.). No dia da antese, as flores foram etiquetadas e os frutos foram colhidos com 34, 41, 48 e 55 dias após a antese (DAA). Para cada idade, em metade dos frutos as sementes foram extraídas imediatamente e a outra metade ficou em repouso por quatorze dias, antes da extração das sementes. Para verificar a qualidade das sementes os seguintes testes foram realizados: teor de água no dia da extração das sementes, massa de 100 sementes, teste de germinação, primeira contagem do teste de germinação e condutividade elétrica. Pode-se concluir que o armazenamento para qualquer idade do fruto melhora o vigor das sementes. Para germinação final, o armazenamento é favorável quando os frutos são colhidos ainda novos (34 e 41 DAA).
\end{abstract}

Termos para indexação: Abelmoschus esculentus, maturação, germinação, vigor, quiabeiro.

\begin{abstract}
The work was carried out at FCA-UNESP, in Botucatu (SP), with the aim of studying the effect of fruit age and post harvest rest on quality of okra seeds cv. Santa Cruz-47 (Abelmoschus esculentus Moench.). At the day of the anthesis, the flowers were labeled and fruits were picked with 34,41,48 and 55 days after the anthesis (DAA). For each age, in half of the fruits the seeds were immediately extracted and the another half was stored for fourteen days before seed extraction. To verify the quality of seeds the following tests were accomplished: seed water content at extraction, weight of 100 seeds, germination test, first counted of germinated seeds and eletrical conductivity. It may be concluded that the fruit storage for any fruit age increases seed vigour, and for final germination, the rest is favorable when fruits are picked still new (34 and 41 DAA).
\end{abstract}

Index terms: Abelmoschus esculentus, maturation, germination, vigor, okra.

(Recebido em 25 de janeiro de 2007 e aprovado em 12 de junho de 2007)

\section{INTRODUÇÃO}

O quiabeiro (Abelmoschus esculentus Moench.), espécie pertencente à família Malvaceae, é originário da África e desenvolve-se melhor nas regiões tropicais, subtropicais e nas áreas mais quentes nas zonas temperadas, desenvolvendo-se bem em temperaturas entre 18 e $35^{\circ} \mathrm{C}$. A faixa ótima para germinação das sementes é entre 20 e $30^{\circ} \mathrm{C}$ (FILGUEIRA, 2000; ZANIN, 1990).

A floração inicia-se de 50 a 60 dias após a semeadura, ocorrendo primeiro na haste principal e três semanas após, nas ramificações (ZANIN, 1990). O período de florescimento e frutificação depende da cultivar e das condições ambientais, ocorrendo maior produção de sementes, em regiões onde a diferença de temperatura diurna e noturna é mínima (FILGUEIRA, 2000; PASSOS et al., 2000).
O cultivo do quiabeiro é realizado, predominantemente, por meio de semeadura direta, onde são colocadas de cinco a oito sementes por cova, conforme as recomendações técnicas para o estado de São Paulo (JORGE et al., 1990), consumindo assim de 4 a $8 \mathrm{Kg}$ de sementes/ha. Esse gasto excessivo de sementes deve-se ao fato delas apresentarem dormência devido à impermeabilidade do tegumento (MEDINA, 1971), que promove uma germinação desuniforme e demorada. Esse fato é acentuado quando a semente possui menos de $12 \%$ de umidade, o que pode ocorrer quando é submetida a um período de secagem muito prolongado ou armazenamento em local com umidade relativa inferior a 60\% (MINAMI et al., 1997).

Em relação à sementes duras, alguns autores admitem que existem diferenças entre cultivares atualmente utilizadas no país quanto a intensidade de sua manifestação.

\footnotetext{
'Engenheira Agrônoma, Doutora em Horticultura - Rua Manoel Álvaro Guimarães, 213 - Vila São Lúcio - 18603-194-Botucatu, SP -marcinhakit@hotmail.com 'Engenheira Agrônoma, Doutora em Horticultura - Departamento de Produção Vegetal - Faculdade de Ciências Agronômicas/FCA - Rua Theodomiro Carmelo, 361 - Vila Carmelo - 18609-580 - Botucatu, SP - ar.godoy@bol.com.br

${ }^{3}$ Engenheiro Agrônomo, Doutor em Genética e Melhoramento de Plantas, Professor Adjunto - Departamento de Produção Vegetal - Faculdade de Ciências Agronômicas/FCA - Rua José Barbosa de Barros, 1780 - Fazenda Lageado - Cx. P. 237 - 18603-970 - Botucatu, SP - ismaeldh@fca.unesp.br
} 
Segundo Viggiano (1991), algumas cultivares apresentam um aumento na porcentagem de sementes duras à medida que os frutos permanecem por mais tempo na planta em condições de campo. O processo de frutificação do quiabeiro tem a tendência de acompanhar o próprio sistema de crescimento da planta. Sendo o hábito de crescimento indeterminado, essa espécie se caracteriza por apresentar o florescimento, a frutificação e a maturação de sementes de forma progressiva na haste principal e nos ramos laterais ao longo do ciclo (SETÚBAL, 1998).

A utilização do sistema de colheita parcelada é determinante para a cultura do quiabeiro, tanto para a produção de sementes, à medida que atingem o estádio de maturação morfológica, como para a produção de frutos visando o mercado "in natura".

De acordo com Setúbal (1987), frutos dos cultivares Santa Cruz 47 e Campinas - 2, quando mantidos na planta após atingir a maturação morfológica, além da repercussão negativa no processo produtivo, a qualidade da semente fica bastante comprometida com o aumento significativo de sementes duras. O mesmo concluiu, ainda, que os métodos de colheita de sementes influenciaram na ocorrência de sementes duras, sendo maior no método de colheita única na senescência das plantas. Nesse estudo, também utilizou-se o cultivar Amarelinho que não apresentou sementes duras mesmo quando a colheita foi realizada de forma condensada, na fase de senescência da planta.

Considerando a importância de se conhecer o momento da maturação do fruto para fins de produção de sementes, Setubal (1987) concluiu que esse foi atingido entre 45 e 55 dias após a antese para os cultivares Campinas2, Santa Cruz 47 e Amarelinho, nas condições de São Manoel - SP.

Outro aspecto que parece influenciar na qualidade das sementes em espécies de frutos carnosos é que, mesmo após a colheita dos frutos, as sementes continuam o seu amadurecimento caso não tenham completado no campo, atingindo níveis máximos de germinação e vigor. Porém, são escassos os estudos em frutos secos. Essa técnica se torna vantajosa, pois são diminuídas as colheitas, uma vez que podem ser colhidos, ao mesmo tempo, frutos com diferentes graus de maturação, de modo que a semente complete sua maturação durante o período de armazenamento e, no caso de quiabo, pode-se evitar colher frutos muito velhos, com maior tendência a apresentar sementes duras.

Já foram relatados efeitos positivos no repouso dos frutos após a colheita para a germinação e vigor das sementes em berinjela (BARBEDO et al., 1994; EGUCHI et al., 1958), pepino (BARBEDO et al., 1997) e abóbora (PEDROSA et al., 1987), entre outras culturas.

Objetivou-se, no presente trabalho, estudar o efeito da idade do fruto e o repouso, após a colheita do mesmo sobre a qualidade de sementes de quiabeiro.

\section{MATERIAL E MÉTODOS}

O experimento foi conduzido no Departamento de Produção Vegetal da Faculdade de Ciências Agronômicas - UNESP - Campus de Botucatu, em estufa agrícola com 7 $\mathrm{m}$ de largura, $20 \mathrm{~m}$ de comprimento e $1,8 \mathrm{~m}$ de pé-direito.

A cultivar utilizada foi a Santa Cruz 47. A semeadura foi realizada no dia 08/01/2004, colocando-se cinco sementes por cova à profundidade de $2 \mathrm{~cm}$ e o espaçamento utilizado foi de 1,0 m entre linhas e 0,40 m entre plantas. Quando as plântulas apresentavam de 3 a 4 folhas definitivas foi realizado o desbaste, deixando-se apenas uma planta por cova.

Foram avaliados 8 tratamentos, em esquema de parcela subdividida, constituídos pela combinação de 4 idades (34, 41, 48 e 55 dias após a antese - DAA) e 2 períodos de repouso após a colheita (sem repouso e 14 dias de repouso após a colheita dos frutos). O delineamento experimental adotado foi em blocos ao acaso, com cinco repetições e seis plantas por parcela.

No dia da antese, as flores foram marcadas com uma etiqueta constando a data de sua abertura, visando a obtenção de frutos, com diferentes idades $(34,41,48$ e 55 DAA). Foram marcados para colheita apenas cinco frutos por planta, sempre na haste principal. Após a colheita, os frutos de cada idade foram divididos em duas partes, sendo que, na primeira, a extração das sementes foi imediata e na segunda parte a extração das sementes foi realizada 14 dias após a colheita, com repouso dos frutos em condições ambientais.

Foram avaliados o teor de água no dia da extração das sementes, massa de 100 sementes, teste de germinação, primeira contagem do teste de germinação e condutividade elétrica.

Para o teor de água foram contadas vinte e cinco sementes por parcela e elas foram pesadas em recipientes adequados e colocadas em estufa de circulação aberta com temperatura de $105^{\circ} \mathrm{C} \pm 3^{\circ} \mathrm{C}$ por 24 horas. Essas foram retiradas da estufa e pesadas novamente e o teor de água foi calculado conforme Brasil (1992).

A massa de cem sementes foi obtida através da contagem de 100 sementes de cada parcela e ajustada para o mesmo teor de água (14\%).

Para o teste de germinação foram utilizadas 5 repetições de 50 sementes por tratamento, instalados em 
rolo de papel-toalha e colocados para germinar à temperatura alternada de 20 e $30^{\circ} \mathrm{C}$, com contagem aos 4 e 21 dias (BRASIL, 1992). A primeira contagem (4 dias após a semeadura), no teste padrão de germinação, foi considerado como teste de vigor, conforme Vieira \& Carvalho (1994).

Para condutividade elétrica foram utilizadas 5 repetições de 25 sementes para cada tratamento. Essas foram pesadas e em seguida foram colocadas para embeber em recipientes plásticos $(200 \mathrm{ml})$, com $75 \mathrm{ml}$ de água destilada e mantidas em germinador por 24 horas à temperatura constante de $25^{\circ} \mathrm{C}$. Após este tempo foi feita a leitura da condutividade elétrica da solução, usando-se condutivímetro modelo Digimed DM 31 (VIEIRA \& CARVALHO, 1994).

Foi realizada a análise de variância com teste F, para cada característica avaliada, no esquema de parcela subdividida. Quando houve efeito significativo (5\%) de idade dos frutos realizou-se análise de regressão. Quando houve efeito de repouso pós-colheita, as médias foram comparadas pelo Teste de Tukey (5\%).

\section{RESULTADOS E DISCUSSÃO}

Para a característica massa de cem sementes não foi observada interação entre os fatores idade dos frutos e armazenamento. $\mathrm{O}$ repouso pós-colheita dos frutos não alterou a massa de 100 sementes, com média de $5,8 \mathrm{~g}$ com ou sem repouso. Observou-se aumento da massa de 100 sementes com a idade dos frutos (Figura 1), ou seja, as sementes continuaram a ganhar massa durante o período, o que já era esperado por ser o padrão de uma semente, durante o processo de maturação da mesma (CARVALHO \& NAKAGAWA, 2000). O aumento médio de massa foi de $0,0344 \mathrm{~g}$, para cada dia que o fruto permanecia na planta.

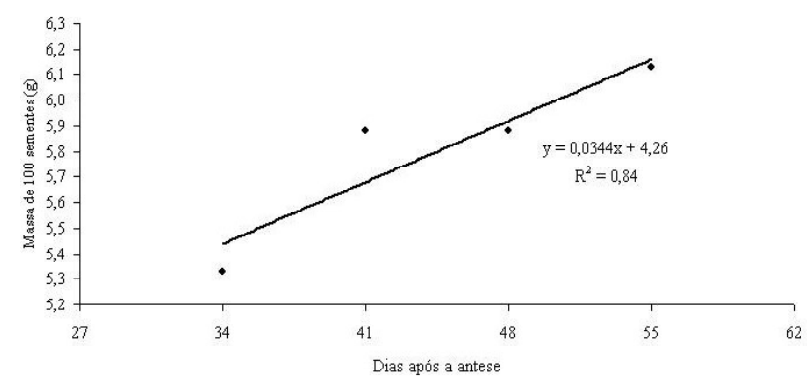

Figura 1 - Massa de 100 de sementes de quiabeiro, em função do número de dias após a antese. Botucatu-SP, FCA/UNESP, 2004.
Quanto ao teor de água, esse era elevado aos 34 dias após a antese $(80,2 \%)$ nas sementes de frutos sem repouso, ocorrendo grande declínio até os 55 dias, com redução média de quase $3 \%$ ao dia, ajustando-se ao modelo linear (Figura 2). Esse é o comportamento normalmente relatado para as sementes durante o processo de maturação (CARVALHO \& NAKAGAWA, 2000). Já nas sementes dos frutos que permaneceram em repouso não houve diferença com a idade dos frutos, mostrando que elas perderam rapidamente água quando completaram a maturação no fruto após a colheita, igualando o teor de água das sementes imaturas (34 DAA) com as mais maduras (55 DAA), com média de $13,8 \%$.

A porcentagem de germinação de sementes de quiabeiro aumentou linearmente, tanto em frutos com como sem repouso pós-colheita, em função da idade em que os frutos foram colhidos (Figura 3). Contudo, o aumento da porcentagem de germinação foi mais acentuado em sementes de frutos sem repouso, ocorrendo redução da diferença de germinação de sementes desses frutos em relação as dos frutos com repouso, com o aumento da idade (Figura 3). As sementes de frutos, com repouso póscolheita, apresentaram maior porcentagem de germinação que as sementes de frutos sem repouso até os 41 DAA. Esse efeito de repouso dos frutos na melhoria da qualidade das sementes normalmente é relatado apenas para frutos que não haviam atingido a maturidade fisiológica, conforme observado em pepino (BARBEDO et al., 1997), berinjela (BARBEDO et al., 1994) e em melancia (ALVARENGA et al., 1984). Aos 55 DAA, quando as sementes já haviam atingido a maturidade fisiológica, o repouso pós-colheita dos frutos não melhorou a qualidade das sementes. Considerando a importância de se conhecer o momento da maturação do fruto para fins de produção de sementes, Setubal (1987) concluiu que esse parâmetro para os cultivares Campinas-2, Santa Cruz 47 e Amarelinho foi atingido entre 45 e 55 dias após a antese, para as condições de São Manoel - SP, o que também foi observado nesse trabalho.

O repouso pós-colheita dos frutos por 14 dias favoreceu o vigor das sementes, promovendo maior germinação na primeira contagem em relação a frutos sem repouso, para todas as idades (Figura 3). Independente do repouso pós-colheita, os dados ajustaram-se à uma equação exponencial quadrática, com maiores porcentagens de germinação estimada para 41 DAA em frutos sem repouso e aos 47 DAA para frutos com repouso (Figura 3). Resultados semelhantes foram encontrados por Barbedo et al. (1997), em pepino; Barbedo et al. (1994), em berinjela, por Alvarenga et al. (1984) em melancia, onde 

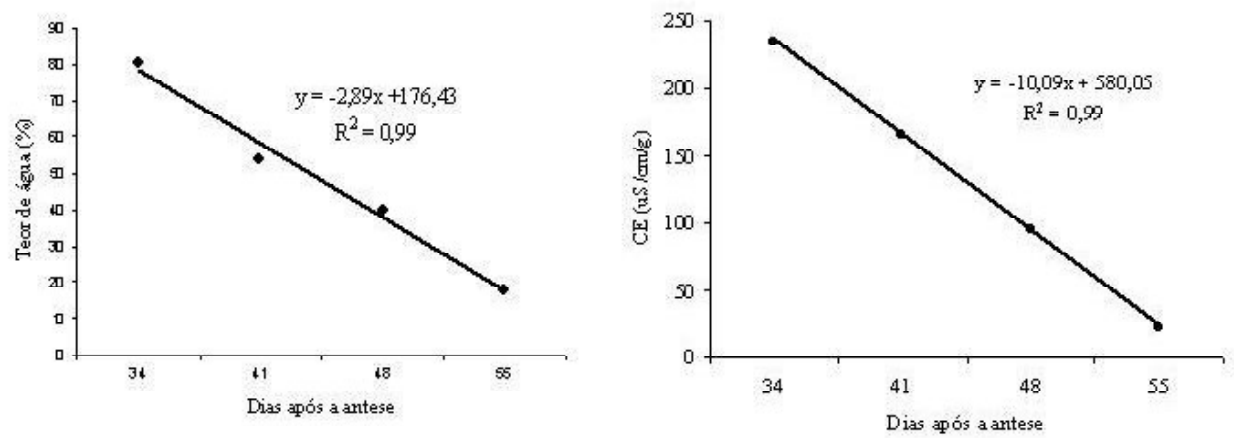

Figura 2 - Teor de água e condutividade elétrica de sementes em frutos de quiabeiro sem repouso pós-colheita, em função do número de dias após a antese. Botucatu-SP, FCA/UNESP, 2004.
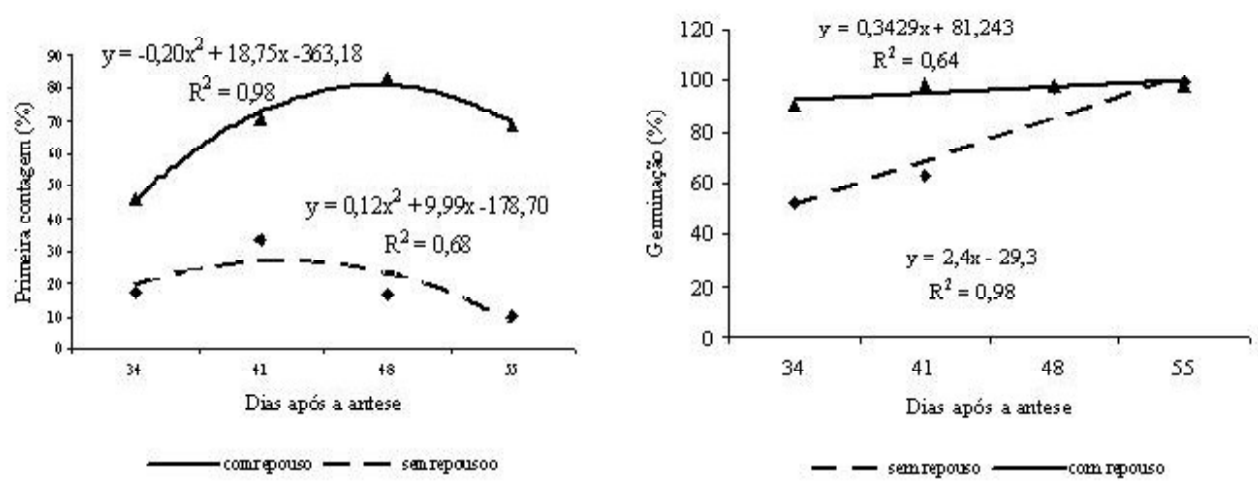

Figura 3 - Primeira contagem e germinação de sementes de quiabeiro de frutos sem e com repouso pós-colheita por 14 dias, em função do número de dias após a antese. Botucatu-SP, FCA/UNESP, 2004.

concluem que o repouso pós-colheita melhorou o vigor das sementes.

A condutividade elétrica reduziu linearmente com a idade dos frutos sem repouso (Figura 2), mostrando que as membranas das células das sementes estavam cada vez mais íntegras. Com repouso dos frutos, não houve diferença entre as idades para condutividade elétrica, novamente mostrando que o repouso iguala a qualidade das sementes imaturas com as maduras, com um valor médio de $55 \mu \mathrm{S} / \mathrm{cm} / \mathrm{g}$. A condutividade elétrica foi menor para frutos com repouso em relação aos sem repouso quando esses eram mais novos (até 41 dias após a antese), porém a partir dos 48 dias não houve efeito do repouso. Por essa característica, demonstra-se que o repouso melhorou a qualidade fisiológica das sementes apenas quando essas foram colhidas mais novas (34 e 41 DAA). Quanto menor a condutividade, melhor a qualidade fisiológica das sementes, visto que ela é função da quantidade de lixiviados na solução, a qual está diretamente relacionada com a integridade das membranas celulares (AOSA, 1983).
Aos 34 dias, os frutos apresentavam-se bem verdes, com pedúnculo verde e sem rachaduras. Aos 41 dias, a coloração começou a passar para um tom amarelado, o pedúnculo ainda estava verde e o fruto ainda não apresentava rachaduras. Aos 48 dias, o fruto ficou marromesverdeado, aparência mais seca, porém o pedúnculo permanecia verde e o fruto sem rachaduras. Aos 55 dias, os frutos apresentavam-se totalmente marrons, aparência bem seca e com rachaduras e com pedúnculo marrom.

No geral, percebe-se que os frutos atingiram a maturidade fisiológica com cerca de 55 dias após a antese, ou seja, totalmente marrons. Porém, com o repouso dos frutos, as sementes continuaram o seu amadurecimento, caso não o tivessem completado no campo, atingindo níveis máximos de germinação e vigor. Isso se torna vantajoso, pois podem ser diminuídas as colheitas, uma vez que podem ser colhidos ao mesmo tempo frutos com diferentes graus de maturação, de modo que a semente complete sua maturação durante o período de repouso pós-colheita. Ressalta-se que o repouso pós-colheita, no geral, não afetou a qualidade das sementes dos frutos que haviam 
atingido a maturidade fisiológica (55 DAA), o que permite a colheita e repouso dos frutos mais novos e maduros ao mesmo tempo. Nesse trabalho, as sementes dos frutos mais novos (34 DAA) com apenas 14 dias de repouso resultaram em sementes com germinação igual aos frutos maduros (55 DAA).

\section{CONCLUSÕES}

Pode-se concluir que o repouso pós-colheita dos frutos melhorou a qualidade das sementes, e que obtémse um aumento linear na qualidade das sementes com o aumento da idade dos frutos.

\section{REFERÊNCIAS BIBLIOGRÁFICAS}

ALVARENGA, E. M.; SILVA, R. F.; ARAÚJO, E. F.; CARDOSO, A. A. Influência da idade e armazenamento póscolheita dos frutos na qualidade de sementes de melancia. Horticultura Brasileira, Brasília, v. 2, n. 2, p. 5-8, 1984.

\section{ASSOCIATION OF OFFICIAL SEED ANALYSTS. Seed vigor testing handbook. [S.1.], 1983. $93 \mathrm{p}$.}

BARBEDO, A. S. C.; ZANIN, A. C. W.; BARBEDO, C. J.; NAKAGAWA, J. Efeitos da idade e do período de repouso pós-colheita dos frutos sobre a qualidade de sementes de berinjela. Horticultura Brasileira, Brasília, v. 12, n. 1, p. 14-18, 1994.

BARBEDO, C. J.; NAKAGAWA, J.; BARBEDO, A. S. C.; ZANIN, A. C. W. Qualidade fisiológica de sementes de pepino cv. Pérola, em função da idade e do tempo de repouso pós-colheita dos frutos. Pesquisa Agropecuária Brasileira, Brasília, v. 32, n. 9, p. 905-913, 1997.

BRASIL. Ministério da Agricultura. Secretaria Nacional de Defesa Agropecuária. Regras para análise de sementes. Brasília, DF, 1992. 188 p.

CARVALHO, N. M.; NAKAGAWA, J. Sementes: ciência, tecnologia e produção. 4. ed. Jaboticabal: Funep, 2000. 588 p.

EGUCHI, T.; OSHIKA, Y.; YAMADA, H. Studies on the effect of maturity on longevity in vegetable seeds. Japan: National Institute of Agricultural Sciences, 1958. p. 145165. (Bulletin, Series E., 7).

FILGUEIRA, F. A. R. Novo manual de olericultura: agrotecnologia moderna na produção e comercialização de hortaliças. Viçosa: UFV, 2000. 402 p.
JORGE, J. A.; LOUREÇÃO, A. L.; ARANHA, C. (Eds.). Instruções agrícolas para o estado de São Paulo. 5. ed. Campinas: Instituto Agronômico, 1990. 233 p. (IAC. Boletim técnico, 200).

MEDINA, P. V. L. Efeito da profundidade de plantio, tipo de leito, modo de semeadura e pré-tratamento na germinação do quiabeiro (Abelmoschus esculentus). 1971. 42 f. Dissertação (Mestrado) - Universidade Federal de Viçosa, Viçosa, 1971.

MINAMI, K.; MODOLO, V. A.; ZANIN, A. C. W.; TESSARIOLI NETO, J. Cultura do quiabeiro: técnicas simples para hortaliça resistente ao calor. Piracicaba: ESALQ/DIB, 1997. 36 p. (Série produtor rural, 3).

PASSOS, F. A.; MELO, A. M. T. de; TAVARES, M.; YUKI, V. A. Avaliação de cor e formato do fruto em quiabo. Horticultura Brasileira, Brasília, v. 18, p. 647-648, jul. 2000. Suplemento.

PEDROSA, J. F.; OLIVEIRA, G. M.; BEZERRA NETO, F.; MONTEIRO, M. R. Influência da idade e armazenamento do fruto na produção e qualidade de sementes de Cucurbita maxima x Cucurbita moschata. Horticultura Brasileira, Brasília, v. 5, n. 2, p. 15-17, 1987.

SETUBAL, J. W. Sementes duras em quiabeiro (Abelmoschus esculentus): efeito de métodos de colheita e da localização dos frutos na planta. 1987. 55 f. Dissertação (Mestrado em Agronomia/Horticultura) - Universidade Estadual Paulista, Botucatu, 1987.

SETUBAL, J. W. Florescimento, frutificação e produção de sementes de quiabeiro (Abelmoschus esculentus (L.) Moench), cv. Amarelinho, em função de diferentes populações de plantas. 1998. $106 \mathrm{f}$. Tese (Doutorado em Agronomia/ Horticultura) - Universidade Estadual Paulista, Botucatu, 1998.

VIEIRA, R. D.; CARVALHO, N. M. Testes de vigor de sementes. Jaboticabal: Funep, 1994. 164 p.

VIGGIANO, J. Situação da produção e importação de sementes de hortaliças. In: ENCONTRO SOBRE PRODUÇÃO E QUALIDADE DE SEMENTES DE HORTALIÇAS, 1991, Brasília, DF. Anais... Brasília, DF: [s.n.], 1991.

ZANIN, A. C. W. Produção de sementes de quiabeiro. In: CASTELLANI, P. D.; NICOLOSI, W. M.; HASEGAWA, M. Produção de sementes de hortaliças. Jaboticabal: Funep, 1990. p. 173-176. 